\title{
The Golden Role of Natural Products in Obesity
}

\author{
Gehan F Abdel Raoof ${ }^{1, *}$, Aya M Z Abd El Kareem² \\ ${ }^{1}$ Pharmacognosy Department, Pharmaceutical and Drug Research Industries Division, National Research Centre, Dokki, Giza \\ 12622, Egypt. \\ ${ }^{2}$ College of Biotechnology, Misr University for Science and Technology (MUST), Egypt.
}

\author{
ARTICLE INFO: \\ Received: 10 Nov 2020 \\ Accepted: 18 Dec 2020 \\ Published: 30 Dec 2020 \\ Corresponding author * \\ Gehan Fawzy Abdel Raoof \\ Kandeel, \\ Researcher (Lecturer) at National \\ Research centre \\ Elbehoos Street, Dokki 12622, \\ Giza, Egypt. \\ E Mail: \\ ahmedkhaled_1@hotmail.com
}

\begin{abstract}
:
Objective: Obesity is considered a serious syndrome that can have a negative impact on the whole systems in the body which leads to many health problems, such as osteoarthritis, heart disease, diabetes, and certain cancers. Up to date reports revealed that there are more than 700 million obese people throughout the world. However, surgery and synthetic drugs may be a choice for the treatment of obesity; they showed unsatisfying results with serious adverse effects. So the best option for the management of obesity is a lifestyle modification together with using natural alternatives that showed the minimal side effects. Natural Products are rich of bioactive compounds that have been used as traditional medicine. Some active natural products were tested by clinical trials and they showed a powerful impact in the treatment of obesity.

Aim: This review is focused on the recent advances in the natural products as anti-obesity potential. A major focus is to highlight the mechanisms of action of natural products as antiobesity agents, as well as the structure-activity studies, preclinical and clinical trials were also discussed.

Results: The current review revealed that natural products include diversity of phytoconstituents that play an important role in the treatment of obesity.
\end{abstract}

Keywords: Anti-obesity, bioactive compounds, natural products, Obesity.

\section{INTRODUCTION}

Obesity is a medical condition in which excess body fat accumulates as a result of imbalance between energy intake and energy expenditure [1]. It is a major public health problem that leads to many diseases, including type 2 diabetes mellitus, hypertension, dyslipidemia, coronary heart disease, some cancers, osteoarthritis, kidney disease, and sleep disorders [2]. Body mass index is used to identify excess weight and obesity based on epidemiologic research. Particularly in females, there is a relation between body mass indexand lifestyle. Body mass index can be calculatedby dividing the weight (kg.) by the height square (cm), Values between 18.5 to 24.9 is normal, while low weight if it lower than, 18.5 and values of 25 and above are considered as obese [3]. Obesity is the major public health problem with about 1.9 billion adults (18 years and older) worldwide are overweight and about 600 million of them are clinically obese [4]. Annually, 30 million people die worldwide due to obesity and overweight [3]. Besides weight loss diet, exercise, and behavioral changes, using anti-obesity drugs have been reputed as a weight loss strategy in overweight and obese individuals. For the treatment of obesity, synthetic pharmaceutical drugs are used imposing high price and many complications. For this reason, patients and researchers are looking for alternative treatment methods such as the use of medicinal plants and their products for the treatment of obesity [5]. So the best option for the management of obesity is a lifestyle modification together with using natural alternatives that showed the minimal side effects. Natural Products are rich of bioactive compounds that have been used as traditional medicine. Some active natural products were tested by clinical trials and they showed a powerful impact in the treatment of obesity [6]. The main objective of this review is to focus on the recent advances in the natural products as anti-obesity potential. A major focus is to highlight the mechanisms of action of natural products as anti-obesity agents, preclinical and clinical trials were also discussed.

\section{OBESITY}

\subsection{Definition}


International Journal of Pharma Research and Health Sciences, 2020; 8 (6): 3248-3255

As it is a significant contributor to the global burden of chronic diseases such as; different types of cancer, type 2 diabetes mellitus and cardiovascular disease, obesity is currently one of the major public health issues. Obesity is a medical disorder, it is found as a result of imbalance between energy consumption and energy spending that leads to accumulation of excess body fat [1].

\subsection{Classification}

There are various methods for measuring the obesity, but the most widely-used method is Body Mass Index (BMI). Body mass index can be determined by dividing the weight (kg.) by the square of the height $(\mathrm{cm})$. BMI is not a percentage of body fat. BMI is only part of a diagnosis of obesity [3].

\subsubsection{Overweight}

Having a BMI in the overweight range (25.0-29.9) is a health concern. Excess weight is hard on your body. It can lead to other health problems including obesity. People who have a BMI in the overweight range and have other health problems (such as type 2 diabetes or heart disease) need to see their healthcare provider for treatment options [7].

\subsubsection{Obesity}

Obesity is a disease where a person's weight is in an unhealthy range (BMI of 30.0-39.9). It is a disease that can lead to other health problems [7].

\subsubsection{Severe Obesity}

The person with BMI greater than 40 is considered as severe obesity case. Severe obesity has the greatest risk of other health problems. People with severe obesity need to see their healthcare provider for treatment options [7]. Increased weight circumference can also be a marker for increased risk even in persons of normal weight.

\subsection{Causes}

The weight of an individual is determined by the balance between intake of calories and energy consumption. The person gains weight if he eats more calories than he burns.A person will lose weight if he eats less calories than he metabolizes. Hence, physical inactivity and overeating are the most common causes of obesity [8,9].

\subsubsection{A diet high in simple carbohydrates}

Blood glucose levels are elevated by carbohydrates, that activate pancreas to release insulin, and insulin stimulates the development of fat tissue and may induce weight gain. Some researchers suggest that simple carbohydrates lead to weight gain because they are absorbed into the bloodstream more easily than complex onesresulting in more insulin being released [1].

\subsubsection{Genetics}

When one ore both parents are obese, person is more likely to develop obesity.Hormones involved in fat control are also affected by genetics.For instance, leptin deficiency is one genetic cause of obesity. When body fat reserves are too high, leptin controls weight by signaling the brain to eat less. If, for some cause, the body cannot produce enough leptin or leptin cannot signal the brain to eat less, this control is lost, and obesity occurs. The role of leptin replacement as a treatment for obesity is under exploration [8].

\subsubsection{Effect of drugs}

Medications associated with weight gain include certain antidepressants, anticonvulsants (medications used in controlling seizures such as carbamazepine and valproate, some diabetes medications (medications used in lowering blood sugar such as insulin, sulfonylureas, and thiazolidinediones), certain hormones such as oral contraceptives, and most corticosteroids such as prednisone. Some high blood pressure medications and antihistamines cause weight gain. The reason for the weight gain with the medications differs for each medication [8].

\subsubsection{Physical inactivity}

Active people burn more calories than sedentary people. There is a strong correlation between physical inactivity and weight gain in both sexes [10].

\subsubsection{Overeating}

Overeating leads to weight gain, especially if the diet is high in fat. Foods high in fat or sugar (for example, fast food, fried food, and sweets) have high energy density (foods that have a lot of calories in a small amount of food). Epidemiologic studies have shown that diets high in fat contribute to weight gain [11].

\subsubsection{Frequency of eating}

The relationship between frequency of eating (how often you eat) and weight is somewhat controversial. There are many reports of overweight people eating less often than people with normal weight. Scientists have observed that people who eat small meals four or five times daily, have lower cholesterol levels and lower and/or more stable blood sugar levels than people who eat two or three large meals daily. One possible explanation is that small frequent meals produce stable insulin levels, whereas large meals cause large spikes of insulin after meals [12].

\subsubsection{Psychological factors}

For some people, emotions influence eating habits. Many people eat excessively in response to emotions such as boredom, sadness, stress, or anger. While most overweight people have no more psychological disturbances than normal weight people, about $30 \%$ of the people who seek treatment for serious weight problems have difficulties with binge eating [12].

\subsubsection{Diseases}

Some diseases such as hypothyroidism, insulin resistance, polycystic ovary syndrome, and Cushing's syndrome are also contributors to obesity. Some diseases, such as Prader-Willi syndrome, can lead to obesity [9].

\subsection{Health problems}

People who have obesity, compared to those with a normal or healthy weight, are at increased risk for many serious diseases and health conditions, including: some types of cancer, cardiovascular disease, low quality of life, gallbladder disease, osteoarthritis, coronary heart disease, type 2 diabetes and dyslipidemia [2]. 
International Journal of Pharma Research and Health Sciences, 2020; 8 (6): 3248-3255

\subsection{Treatment}

\subsubsection{Lifestyle Modification}

The change in lifestyle includes introduction of behavioral and dietary changes that can be sustained indefinitely to promote health [13].

\subsubsection{Dietary interventions}

Dietary interventions for obesity are designed to create a negative energy balance (i.e., calories ingested < calories expended) by reducing daily energy intake below energy requirements. Uniformly, however, greater energy deficits result in greater weight losses [14].

\subsubsection{Physical activity}

The physical activity causes improving cardiovascular fitness, sparing fat-free mass during weight loss and increasing in calorie expenditure. Physical activity, however, produces minimal weight loss in the absence of caloric restriction. The greatest benefit of physical activity is in facilitating the maintenance of weight loss. Case studies have shown that people who exercise regularly are more successful in maintaining weight losses than are those who do not exercise [15].

\subsubsection{Medications}

As BMI or disease risk increase, more intensive options are available for the treatment of obesity. Pharmacotherapy is recommended for individuals with a BMI $\geq 30 \mathrm{~kg} / \mathrm{m}^{2}$. Two medications - sibutramine (Meridia) and orlistat (Xenical) are approved by the Food and Drug Administration for the induction and maintenance of weight loss[16].There are several barriers, however, to the long-term use of weight loss medications, including findings that most patients must pay out-of-pocket for anti-obesity agents[17].

\subsubsection{Surgical Interventions}

Bariatric surgery is appropriate only for those individuals with a BMI $\geq 40 \mathrm{~kg} / \mathrm{m}^{2}$ or BMI $\geq 35 \mathrm{~kg} / \mathrm{m}^{2}$ in the presence of comorbidities [18]. The two most common surgical procedures for obesity are vertical banded gastroplasty (VBG) and gastric bypass (GB). Both entail isolating a small (15- to 30-ml) pouch of stomach with a line of staples, thereby drastically limiting food intake. In VBG, the pouch empties into the remaining stomach, where the digestive process continues as normal. GB, however, not only restricts food intake, but also reduces absorption by bypassing the remaining stomach and $45-150 \mathrm{~cm}$ of small intestine. Bariatric surgery produces significant improvements in hypertension, asthma, sleep apnea, and diabetes. Improvements in mood have also been reported, but they appear to wane with time [19].

\subsubsection{A new approach for the treatment}

Actually, medications for the treatment of obesity are of two types; orlistat, which inhibits the absorption of fat via pancreatic lipase inhibition, and subutramine which is an appetite suppressant. Both medications induce complications such as; constipation, insomnia, headache dry mouth and increased blood pressure .In 1997, the US FDA approved subutramine for the treatment of obesity. But in 2010due to increased cardiovascular events and strokes, the drug was withdrawn from the market. Some medications can be abused such as diethylpropion and phentermine and hence are approved for short term use. So the conventional therapy of obesity mainly involves synthetic moieties and surgical procedures, which has many harmful side effects and chances of recurrence with severity. At the present, using anti-obesity drugs from natural products is in need because of the high cost and complications of synthetic drugs [4, 8].

\subsubsection{Natural Products against obesity}

This review focus on natural phyto extracts with their mechanism of action and their preclinical experimental model for further scientific research. Table 1 showed some important developments in the field of natural drug developments. The various phytoconstituents from these plants have shown more than one type of anti-obesity mechanisms including; increasing expression of PPAR- $\alpha$ and PPAR- $\beta$, inhibition of ghrelin, reducing accumulation of white adipose tissue, regulating gene expression, inducing anorexia, pancreatic lipase inhibition and regulating plasma lipid profile. Furthermore, the major mechanism is reducing the lipid levels of plasma followed by suppression the activity of pancreatic lipase enzyme. While, no detailed researches highlight the molecular mechanism for anti- obesity activity. So, researchers have been motivated by the increasing threat of obesity to global health to put more effort into discovering an effective mechanism of action at molecular level. 
International Journal of Pharma Research and Health Sciences, 2020; 8 (6): 3248-3255

Table 1: Medicinal plant for anti obesity activity

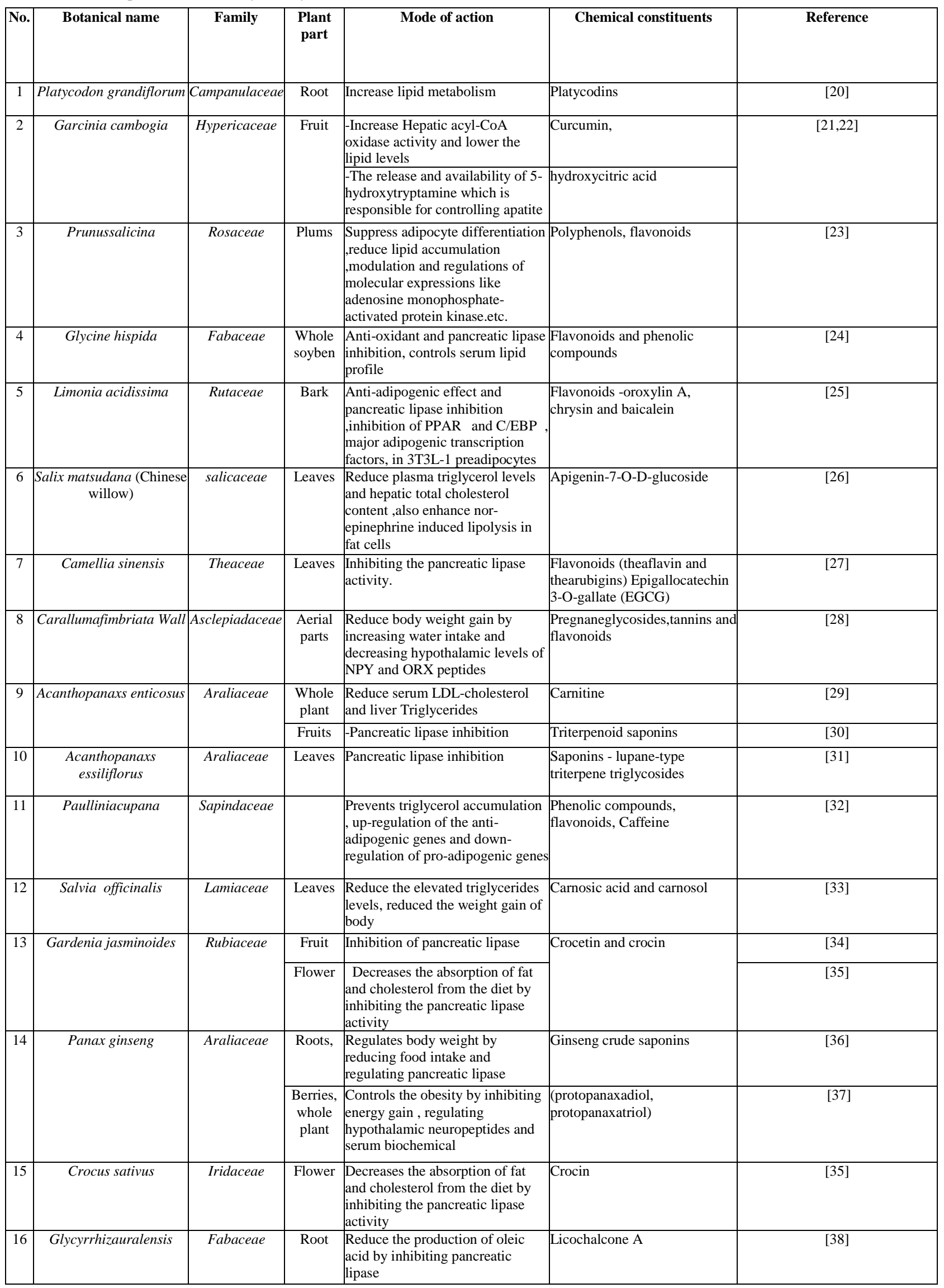


International Journal of Pharma Research and Health Sciences, 2020; 8 (6): 3248-3255

\begin{tabular}{|c|c|c|c|c|c|c|}
\hline 17 & Cassia siamea & Magnoliaceae & Bark & $\begin{array}{l}\text { Anti-adipogenic effect and } \\
\text { pancreatic lipase inhibition }\end{array}$ & $\begin{array}{l}\text { Flavonoids -oroxylin A, } \\
\text { chrysin and baicalein }\end{array}$ & [25] \\
\hline 18 & Nelumbonucifera gaertn & Nymphaeceae & Leaves & $\begin{array}{l}\text { Accelerates lipid metabolism } \\
\text { inhibition of alpha amylase and } \\
\text { lipase, lower the serum total } \\
\text { cholesterol, triglycerides, low } \\
\text { density lipoproteins levels }\end{array}$ & Phenolic compounds & [39-41] \\
\hline 19 & Aesculus turbinate & Sapindaceae & Seeds & Inhibition of pancreatic lipase & Saponins & [42] \\
\hline 20 & Cudraniatricuspidata & Moraceae & $\begin{array}{l}\text { Whole } \\
\text { soyben }\end{array}$ & $\begin{array}{l}\text { Anti-oxidant and pancreatic lipase } \\
\text { inhibition }\end{array}$ & Polyphenolic compounds & [24] \\
\hline 21 & Citrus depressa & Rutaceae & Fruits & $\begin{array}{l}\text { Reduce white adipose tissue, } \\
\text { reduced the plasma triglyceride, } \\
\text { decreasing leptin levels }\end{array}$ & Flavonoids & [43] \\
\hline 22 & Carissa carandas & Apocynaceae & Bark & $\begin{array}{l}\text { Anti-adipogenic effect and } \\
\text { pancreatic lipase inhibition }\end{array}$ & $\begin{array}{l}\text { Flavonoids chrysin and } \\
\text { baicalein }\end{array}$ & [25] \\
\hline \multirow[t]{2}{*}{23} & Coffeaarabica & Rubiaceae & $\begin{array}{c}\text { Beans or } \\
\text { seeds }\end{array}$ & Increase Energy expenditure & Polyphenols,chlorogenic acids & {$[44,45]$} \\
\hline & (Green Coffee bean) & & & & & \\
\hline 24 & Citrus unshiu & Rutaceae & $\begin{array}{l}\text { Dried } \\
\text { peels }\end{array}$ & $\begin{array}{l}\text { Significant reduction of serum } \\
\text { triacylglycerol, total cholesterol } \\
\text { through pancreatic lipase } \\
\text { inhibition }\end{array}$ & $\begin{array}{l}\text { Flavonoids and phenolic } \\
\text { compounds }\end{array}$ & [46] \\
\hline 25 & Loniceracaerulea & Caprifoliaceae & $\begin{array}{l}\text { Whole } \\
\text { soyben }\end{array}$ & $\begin{array}{l}\text { Anti-oxidant and pancreatic lipase } \\
\text { inhibition, controls serum lipid } \\
\text { profile }\end{array}$ & $\begin{array}{l}\text { Flavonoids and phenolic } \\
\text { compounds }\end{array}$ & [24] \\
\hline 26 & Swertiachirayita & Gentianaceae & Bark & $\begin{array}{c}\text { Anti-adipogenic effect and } \\
\text { pancreatic lipase inhibition }\end{array}$ & $\begin{array}{l}\text { Flavonoids -oroxylin A, and } \\
\text { chrysin }\end{array}$ & [25] \\
\hline 27 & Diospyros kaki & Ebenaceae & $\begin{array}{l}\text { Unripe } \\
\text { fruit }\end{array}$ & \begin{tabular}{|l|} 
Significant reduction of serum \\
triacylglycerol, total \\
cholesterol levels, and visceral fat \\
through pancreatic lipase \\
inhibition
\end{tabular} & $\begin{array}{l}\text { Flavonoids and phenolic } \\
\text { compounds }\end{array}$ & [46] \\
\hline 28 & Capsicum annuum & Solanaceae & Flowers & $\begin{array}{l}\text { Anti-oxidant and pancreatic } \\
\text { lipase inhibition }\end{array}$ & $\begin{array}{l}\text { Flavonoids and phenolic } \\
\text { compounds }\end{array}$ & [47] \\
\hline 29 & Oroxylumindicum & Bignoniaceae & Bark & $\begin{array}{l}\text { Anti-adipogenic effect and } \\
\text { pancreatic lipase inhibition }\end{array}$ & Flavonoids & [25] \\
\hline 30 & Acacia mearnsii & Mimosaceae & Bark & $\begin{array}{l}\text { Suppression of body weight, } \\
\text { maintain plasma glucose \& insulin }\end{array}$ & Polyphenols - catechins & [48] \\
\hline 31 & Capparis decidua & Capparaceae & Bark & $\begin{array}{l}\text { Anti-adipogenic effect and } \\
\text { pancreatic lipase inhibition }\end{array}$ & Flavonoids & [25] \\
\hline 32 & Cuscuta pedicellata & Convolvulaceae & & $\begin{array}{l}\text { The reduction of insulin resistance } \\
\text { and glucose tolerance, improving } \\
\text { the cellular energy homeostasis } \\
\text { and possession of antioxidant } \\
\text { activity }\end{array}$ & $\begin{array}{l}\text { Naringenin , kaempferol } \\
\text { aromadendrin , quercetin }\end{array}$ & {$[1,49,50]$} \\
\hline 33 & $\begin{array}{l}\text { Zingiber officinale } \\
\text { (Ginger) }\end{array}$ & Zingiberaceae & rhizomes & $\begin{array}{l}\text { Increasing thermogenesis and } \\
\text { energy expenditure, increasing the } \\
\text { lipolysis, inhibition of the } \\
\text { intestinal absorption of dietary fat, } \\
\text { and controlling the appetite }\end{array}$ & $\begin{array}{l}\text { volatile oils including } \\
\text { zingiberene, gingerol, shogaol, } \\
\text { and zingerone. }\end{array}$ & [51-55] \\
\hline 34 & Cinnamomum zeylanicum & Lauraceae & Bark & $\begin{array}{l}\text {-Significantly reduced fat mass at } \\
\text { the dosages of } 2 \mathrm{~g} / \mathrm{d} \text {, when } \\
\text { administered for } 12 \text { weeks. } \\
\text { Inhibition of adipocyte by } \\
\text { polyphenolic compounds; also } \\
\text { they inhibited lipolysis, } \\
\text { lipogenesis and intestinal lipid } \\
\text { absorption that they tend to } \\
\text { lowering weight. }\end{array}$ & $\begin{array}{l}\text { Polyphenolic compounds } \\
\text { cinnamaldehyde, cinnamate, } \\
\text { cinnamic acid and eugenol }\end{array}$ & {$[51,56-60]$} \\
\hline
\end{tabular}

\section{CONCLUSION}

This review points to the role of natural product in the management of obesity. It revealed that natural products include diversity of phytoconstituents that play an important role in the treatment of obesity. Furthermore, more researches are required to confirm the effect of natural product as anti-obesity agents and to enter the drug discovery field.

\section{REFERENCES}

1. Marrelli M, Statti G, Conforti F. A Review of Biologically Active Natural Products from 
International Journal of Pharma Research and Health Sciences, 2020; 8 (6): 3248-3255

MediterraneanWild Edible Plants: Benefits in the Treatment of Obesity and Its Related Disorders. Molecules 2020; 25: 649-69.

2. Payab M, Ranjbar S H, Aletaha A, Ghasemi N, Qorbani M,Atlasi R, Abdollahi M, Larijani B. Efficacy, safety, and mechanisms of herbal medicines used in the treatment of obesity. Medicine 2018; 17: 6-12.

3. Bahmani M, Eftekhari Z, Saki K, Moghadam E F,JelodariM, KopaeiM R. Obesity Phytotherapy: Review of Native Herbs Used in Traditional Medicine for Obesity. J Evid Based Integr Med 2015; 21: 228-34.

4. Patra S,Nithya S,Srinithya B, MeenakshiS M. Review of Medicinal Plants for Anti-Obesity Activity. Transl Biomed 2015; 11: 320-32.

5. Payab M,Ranjbar S H,Shahbal N, Qorbani M,Aletaha A, Aminjan H H, Soltani A, Khatami F,Nikfar S, Hassani S, Abdollahi M, Bagher L. Effect of the herbal medicines in obesity and metabolic syndrome: A systematic review and meta-analysis of clinical trials. Phytother Res 2019; 12: 1-20.

6. Barrea L, Altieri B, Polese B, Conno B D, Muscogiuri G, Colao A. Nutritionist and obesity: brief overview on efficacy, safety, and drug interactions of the main weight-loss dietary supplements. Int J Obes Suppl 2019; 9: 32-49.

7. Aronne L J. Classification of Obesity and Assessment of Obesity-Related Health Risks. Obes Res 2002; 10: 10515 .

8. Karri S, Sharma S, Hatware K, Patil K. Natural antiobesity agents and their therapeutic role in management of obesity: A future trend perspective. Biomed Pharmacother 2019; 110: 224-38.

9. Wright S M, AronneL J. Causes of obesity. Abdominal Published 2012; 37: 730-2.

10. Kimm S Y, Glynn N W, Kriska A M. Decline in physical activity in black girls and white girls during adolescence. The New England Journal of Medicine 2002; 347: 709-15.

11. Bora K. Obesity: Causes and Consequences. Metabolic Bone Disease and Related Research 2016; 30: 223-42.

12. Pradeepa R,Anjana R M, Joshi S R, Bhansali A, Deepa M, Joshi P P. Prevalence of generalized and abdominal obesity in urban and rural India - the ICMR INDIAB Study (Phase 1) [ICMR-INDIAB-3]. Ind J Med Res 2015;142: 139-50.

13. Fabricatore A N,WaddenT A. Treatment of Obesity: An Overview. Clin Diabetes 2003; 21: 67-72.

14. Ayyad C, and Andersen T. Long-term efficacy of dietary treatment of obesity: a systematic review of studies published between1931 and 1999. Obes Rev 2000; 1: 113-9.

15. Bensimhon D R, Kraus W E, Donahue M P.Obesity and physical activity: a review. Am Heart J 2006; 151: 598-603.
16. Gray L J,Cooper N, Dunkley A, Warren F C, Ara R, Abrams K, Davies M J, Khunti K. A systematic review and mixed treatment comparison of pharmacological interventions for the treatment of obesity. Obes Rev 2012; 13: 483-98.

17. Rodgers R J, TschöpM H,and Wilding J P H. Antiobesity drugs: past, present and future. DMM 2012; 5: 621-6.

18. Albaugh V L, and AbumradN N. Surgical treatment of obesity. F1000 Research 2018; 20 :617-30.

19. Dixon J B, Straznicky N E, Lambert E A,Schlaich M P, Gavin W. Surgical approaches to the treatment of obesity.Nat Rev Gastroenterol Hepatol 2011; 8: 429-37.

20. Han L K, XuB J, KimuraY, ZhengY, OkudaH. Platycodi radix Affects Lipid Metabolism in Mice with High Fat Diet-Induced Obesity. J Nutr 2000; 130: 2760-4.

21. Asai A, Miyazawa T. Dietary curcuminoids prevent high-fat diet-induced lipid accumulation in rat liver and epididymal adipose tissue. J Nutr 2001; 131: 2932-5.

22. Ohia S E, Opere C A, Le DayA M, Bagchi M, Bagchi D, Stohs S J. Safety and mechanism of appetite suppression by a novel hydroxycitric acid extract (HCASX). Mol Cell Biochem 2002; 238: 89-103.

23. Choe W K, KangB T., Kim S O. Water-extracted plum (Prunussalicina L. Cv. Soldam) attenuates adipogenesis in murine 3T3-L1 adipocyte cells through the PI3K/Akt signaling pathway. Exp Ther Med 2018; 15: 1608-15.

24. Suh D H, Jung E S, Park H M, Kim S H, Lee S, Jo Y H, Lee M K, Jung G, Do S G, Lee C H. Comparison of metabolites variation and antiobesity effects of fermented versus nonfermented mixtures of Cudraniatricuspidata, Loniceracaerulea, and soybean according to fermentation in vitro and in vivo. PLoS 2016; 11: 317-36.

25. Mangal P, Khare P, Jagtap S, Bishnoi M, Kondepudi K K, Bhutani K K. Screening of six Ayurvedic medicinal plants for anti-obesity potential: an investigation on bioactive constituents from Oroxylumindicum (L.) Kurz bark. J Ethnopharmacol 2017; 197: 138-46.

26. Han L, Sumiyoshi M, Zheng Y, Okuda H, Kimura Y. Anti-obesity action of Salix matsudana leaves (Part 2). Isolation of anti-obesity effectors from polyphenol fractions of Salix matsudana. Phytother Res 2003; 17: 1195-8.

27. Nakai M, Fukui Y,Asami S, Toyoda Y, Iwashita T, Shibata H, Mitsunaga T, Hashimoto F,Kiso Y. Inhibitory effects of oolong tea polyphenols on pancreatic lipase in vitro. J Agric Food Chem 2005; 53 : 4593-8.

28. Vitalone A, Di Sotto A, Mammola C L, Heyn R, Miglietta S, Mariani P,Sciubba F, Passarelli F,NativioP, MazzantiG. Phytochemical analysis and effects on ingestivebehaviour of a Carallumafimbriata extract. Food Chem Toxicol 2017; 108: 63-73. 
International Journal of Pharma Research and Health Sciences, 2020; 8 (6): 3248-3255

29. Cha Y S, Rhee S J, HeoY R. Acanthopanaxsenticosus extract prepared from cultured cells decreases adiposity and obesity indices in C57BL/6J mice fed a high fat diet. J Med Food 2004; 7: 422-9.

30. Li F, Li W, Fu H, Zhang Q, Koike K. Pancreatic lipase-inhibiting triterpenoid saponins from fruits of Acanthopanaxsenticosus. Chem Pharm Bull 2007;55: 1087-9.

31. Yoshizumi K, Hirano K, Ando H, Hirai Y, Ida Y, Tsuji T, Tanaka T,SatouchiK, TeraoJ. Lupane-type saponins from leaves of Acanthopanaxsessiliflorus and their inhibitory activity on pancreatic lipase. J Agric Food Chem 2006; 54: 335-41.

32. Lima N S,Numata E P, Mesquita L M S, Dias P H,Vilegas W, GamberoA, Ribeiro M L. Modulatory effects of guarana (Paulliniacupana) on Adipogenesis. Nutrients 2017; 9: 635-53.

33. Ninomiya $K$, Matsuda $H$, Shimoda $H$, Nishida $N$, Kasajima N, Yoshino T, et al. Carnosic acid, a new class of lipid absorption inhibitor from sage. Bioorg Med Chem Lett 2004; 14: 1943-6.

34. Lee I A, Lee J H, BaekN I, Kim D H. Antihyperlipidemic effect of crocin isolated from the fruits of Gardenia jasminoides and its metabolite crocetin. Biol Pharm Bull 2015; 28: 2106-10.

35. Sheng L, Qian Z, Zheng S, Xi L. Mechanism of hypolipidemic effect of crocin in rats: crocin inhibits pancreatic lipase. Eur J Pharmacol 2006; 543: 116-22.

36. Kim J H, Hahm D H, Yang D C, Kim J H, Lee H J, Shim I. Effect of crude saponin of Korean red ginseng on high-fat diet-induced obesity in the rat. $\mathbf{J}$ Pharmacol Sci 2005; 97: 124-31.

37. Kim J H, Kang S A, Han S, Shim I. Comparison of the antiobesity effects of the Protopanaxadiol-and protopanaxatriol-type saponins of red ginseng. Phytother Res 2009; 23: 78-85.

38. Won S R, Kim S K, Kim Y M, Lee P H,Ryu J H, Kim J $\mathrm{W}$, et al. Licochalcone A: a lipase inhibitor from the roots of Glycyrrhizauralensis. Food Res Int 2007; 40: 1046-50.

39. Ono Y, Hattori E,Fukaya Y, Imai S, OhizumiY. Antiobesity effect of Nelumbonucifera leaves extract in mice and rats. J Ethnopharmacol 2006;106: 238-44.

40. Du H, You J S, Zhao X, Park J Y, Kim S H, Chang K J. Antiobesity and hypolipidemic effects of lotus leaf hot water extract with taurine supplementation in rats fed a high fat diet. J Biomed Sci 2010; 17: 42-54.

41. Liu S, Li D, Huang B, Chen Y, Lu X, Wang Y. Inhibition of pancreatic lipase, $\alpha$-glucosidase, $\alpha$ amylase, and hypolipidemic effects of the total flavonoids from Nelumbonucifera leaves. J Ethnopharmacol 2013; 149: 263-9.

42. Hu J N, Zhu X M, Han L K, Saito M, Sun Y S, Yoshikawa M, Kimura Y, Zheng Y N. Anti-obesity effects of escins extracted from the seeds of
Aesculusturbinata Blume (Hippocastanaceae). Chem Pharm Bull 2008; 56: 12-6.

43. Lee Y S, Cha B Y, Saito K, Choi S S , Wang X X, Choi B K,Yonezawa T, Teruya T, Nagai K, Woo J TEffects of a Citrus depressaHayata (shiikuwasa) extract on obesity in high-fat diet-induced obese mice. Phytomedicine 2011;18: 648-54.

44. Murase T, Misawa K, Minegishi Y, Aoki M, Ominami H, Suzuki Y, Shibuya Y, HaseT. Coffee polyphenols suppress diet-induced body fat accumulation by downregulating SREBP-1c and related molecules in C57BL/6J mice. Am J Physiol Endocrinol Metab 2010; 300: 122-33.

45. Shimoda H, Seki E, Aitani M. Inhibitory effect of green coffee bean extract on fat accumulation and body weight gain in mice. BMC Complement Altern Med 2006; 6: $1-9$.

46. Kim G N, Shin M R, Shin S H, Lee A R, Lee J Y, Seo B I, Kim M Y, Kim T H, Noh J S, Rhee M H. Study of antiobesity effect through inhibition of pancreatic lipase activity of Diospyros kaki fruit and Citrus unshiu peel. Biomed Res Int2016; 300: 122-33.

47. Tan S, Gao B, Tao Y, GuoJ, Su Z. Antiobese effects of capsaicin-chitosan microsphere (CCMS) in obese rats induced by high fat diet.J Agric Food Chem 2015; 62: 1866-74.

48. Ogawa S,YazakiY. Tannins from Acacia mearnsii De Wild. Bark: Tannin Determination and Biological Activities. Molecules 2018; 23: 837-45.

49. ZekrySH, Abo-elmattyDM, ZayedRA, RadwanMM, ElSohlyMA, HassaneanHA, AhmedSA. Effect of metabolites isolated from Cuscuta pedicellata on high fat diet-fed rats, Med Chem Res 2015; 24:1964-73.

50. Mehanna E T, El-sayedNM, Ibrahim AK, AhmedS A. ,Abo-Elmatty D M. Isolated compounds from Cuscuta pedicellata ameliorate oxidative stress and upregulate expression of some energy regulatory genes in high fat diet induced obesity in rats. Biomed Pharmacother 2018;108:1253-8.

51. Abdel Raoof G F, Mohamed K Y, Mohammed H M. Phytochemical Evaluation, Anti-obesity and Antihyperlipidemic Effects of Combined Administration of Green Coffee, Cinnamon and Ginger. Sciencepc 2017; 5: 80-4.

52. Attari V E, Mahdavi A M, Javadivala Z,Mahluji S, VahedS Z, OstadrahimiA. A systematic review of the anti-obesity and weight lowering effect of ginger (Zingiberofficinale Roscoe) and its mechanisms of action. Phytother Res 2017; 32:577-85.

53. Akhani S P, Vishwakarma S L, Goyal R K. Antidiabetic activity of Zingiber officinale in streptozotocin-induced type I diabetic rats. J Pharm Pharmacol 2004; 56: 101-5.

54. El Rokhel S M, Yassin N A, El-Shenawy S M, Ibrahim B M. Antihypercholesterolaemic effect of ginger 
International Journal of Pharma Research and Health Sciences, 2020; 8 (6): 3248-3255

rhizome (Zingibero fficinale) in rats. Inflammopharmacology 2010; 18: 309-15.

55. Abdel-Azeem A S, Hegazy A M., Ibrahim K S, Farrag A R, El-Sayed E M Hepatoprotective, antioxidant, and ameliorative effects of ginger (Zingiber officinale Roscoe) and vitamin $\mathrm{E}$ in acetaminophen treated rats. $\mathrm{J}$ Diet Suppl 2013;10: 195-209.

56. Mousavi S M, Rahmani J, Varkaneh H K, Sheikhi A, LarijaniB, Esmaillzadeh A. Cinnamon supplementation positively affects obesity: A systematic review and dose-response meta-analysis of randomized controlled trials. Clin Nutr 2020; 39: 123-33.

57. Azab K S h, Mostafa A H, Ali E M, Abdel-Aziz M A. Cinnamon extract ameliorates ionizing gradiationinduced cellular injury in rats. Ecotoxicol Environ Saf, 2011;74: 2324-9.

58. Vafa M, Mohammadi F, Shidfar F, Sormaghi M S, Heidari I, Golestan B, et al. Effects of cinnamon consumption on glycemic status, lipid profile and body composition in type 2 diabetic patients. Int J Prev Med 2012; 3: 531-6.

59. Shatwan I A, Ahmed L A, Badkook M M. Effect of barley flour, crude cinnamon, and their combination on glycemia, dyslipidemia, and adipose tissue hormones in type 2 diabeticrats. J Med Food 2013;16: 656-62.

60. Lee S. C., Xu W. X., Lin L. Y., Yang J. J., Liu C. T. Chemical composition and hypoglycemic and pancreasprotective effect of leaf essential oil from indigenous cinnamon (Cinnamomum osmophloeum Kanehira). J Agric Food Chem 2013;61:4905.

\section{Conflict of Interest: None Source of Funding: Nil}

